PREHOSPITAL CARE

\title{
Less IS less: a randomised controlled trial comparing cautious and rapid nalbuphine dosing regimens
}

\author{
M Woollard, R Whiffield, K Smith, T Jones, G Thomas, G Thomas, C Hinton
}

Emerg Med J 2004;21:362-364. doi: 10.1136/emj.2004.014324

See end of article for authors' affiliations

Correspondence to: Malcolm Woollard, The Old Plough, Llangattock, Powys NP8 1HU, UK; Malcolm.woollard@ ukgateway.net

Accepted for publication 4 February 2004

\begin{abstract}
Objective: This study aimed to determine which of two paramedic administered nalbuphine dosing regimens combined the greater analgesic effect with the minimum of adverse events.

Methods: Patients suffering from chest pain or trauma were randomised to receive either a rapid dosing regimen ( $10 \mathrm{mg}$ over 30 seconds, repeated once after three minutes if pain score remained above three) or a cautious regimen $(5 \mathrm{mg}$ over two minutes, repeated at three minute intervals if pain score remained above three to a maximum dose of $20 \mathrm{mg}$ ). Data were collected on analgesic effectiveness, changes in vital signs, and patient reported side effects.

Results: The pain score fell by a mean of 4.29 and 3.49 in the rapid and cautious regimen groups respectively (difference $=0.79,95 \% \mathrm{Cl} 0.09$ to $1.5, \mathrm{p}=0.028$ ). However, over half the patients in both groups continued to suffer significant pain on arrival at hospital. There were no significant changes in vital signs after nalbuphine, but there was a greater incidence of patient reported drowsiness in rapid regimen patients ( $42 \%$ compared with $21 \%, 95 \% \mathrm{Cl}=6.96$ to $34.12 \%, p=0.003$ ).

Conclusion: A rapid dosing regimen of nalbuphine using $10 \mathrm{mg}$ increments is more effective than and equally as safe as a cautious regimen using $5 \mathrm{mg}$ increments. Further research is required to determine if a maximum dose exceeding $20 \mathrm{mg}$ would result in fewer patients continuing to suffer significant pain before arrival at hospital.
\end{abstract}

\section{METHODS}

\section{Study design}

This randomised controlled trial compared two dosing regimens of paramedic administered nalbuphine hydrochloride (Du Pont Pharmaceuticals Limited, Letchworth Garden City, UK). Subjects in the rapid regimen group received $10 \mathrm{mg}$ nalbuphine over 30 seconds, repeated once after three minutes if their pain score remained above three. Those treated with the cautious regimen received $5 \mathrm{mg}$ nalbuphine over two minutes, repeated at three minute intervals if their pain score remained above three to a maximum dose of $20 \mathrm{mg}$.

Patients were asked to score their pain using a numerical rating scale (NRS) graded from 0-10, with four or higher

indicating moderate to severe pain. The NRS has been recommended for use in a variety of settings, ${ }^{7}$ avoids underestimation or over-estimation of pain by independent observers, ${ }^{8}$ and correlates well with the validated visual analogue scale. ${ }^{9-12}$ Paramedics gave a standardised explanation of the NRS:

"On a scale of 0 to 10, with zero representing no pain and 10 being the worst pain you can imagine, what score would you give to the pain you are experiencing now?"

Patients aged 18 or over with pain scores of more than three associated with long bone injury, burns, or ischaemic heart disease were recruited. Patients not meeting the criteria for nalbuphine administration or who had previously received analgesia (other than Entonox) were excluded.

Six hundred forms identifying the regimen to be used were randomised using statistical software (SPSS, version 9.0.0, SPSS Inc, Chicago), assigned a unique number, and placed in opaque envelopes. These were distributed in consecutively numbered groups of 10 to each participating ambulance. Paramedics opened the envelope with the lowest remaining number after recruitment of each patient.

If the attending paramedic judged the patient was not too distressed, verbal informed consent was obtained. An information sheet, including a form to indicate their wish to withdraw their data from the study, was given to all patients after hospital admission. Ethics approval was obtained from the Bro Taf and North Wales Health Authority (Central and East) committees.

Sample sizes for a range of outcome variables were calculated and the largest selected for adoption. Based on a $1.74 \%$ incidence of nausea in a previous study, ${ }^{6} 152$ subjects were required in total to detect a between groups difference of $10 \%$ with an $\alpha$ of $5 \%$ and a power of $90 \%$ ( $\chi^{2}$ test).

\section{Outcome measures and statistical analysis}

Between groups comparisons were made for homogeneity, analgesic efficacy, changes in vital signs, side effects, and for evidence of antagonism of hospital administered opioids. 
Data were analysed using SPSS (version 9.0.0, SPSS Inc, Chicago, USA). The Mann-Whitney $U$ test was used for between groups comparisons of non-parametric data. Student's unpaired $t$ test was used for between groups comparisons of changes in pain score and pulse rate. Fisher's exact test was used for analysis of contingency tables. StatsDirect (version 1.9.8, CamCode, Ashwell, UK) was used to calculate $\mathrm{p}$ values and $95 \%$ confidence intervals for differences in proportions.

\section{RESULTS}

\section{Recruitment}

Recruitment is described in the Consort flowchart (fig l).. ${ }^{13}$

\section{Heterogeneity of groups}

Before nalbuphine administration there were no significant between groups differences in age, ratio of male to female subjects, on-scene time, journey time to hospital, ratio of chest pain to trauma patients, vital signs or pain scores (data available on request).

\section{Analgesic efficacy and side effects}

The rapid dosing regimen resulted in a significantly greater reduction in pain score. There were no significant between groups differences for changes in vital signs after nalbuphine. However, significantly more side effects occurred in the rapid regimen group, largely explained by a greater incidence of patient reported drowsiness (table 1).

Hospital staff reported signs of antagonism to hospital administered opioids in two patients in each group.

\section{DISCUSSION}

Rapid dosing resulted in a greater decrease in pain score. Although the difference of 0.79 is small, it represents a benefit that patients can perceive. ${ }^{8}$ However, over half the patients in both groups continued to suffer from significant pain before arrival at hospital.

Rapid regimen patients suffered significantly more patient reported side effects, largely accounted for by an increased incidence of patient reported drowsiness. This was not associated with significant changes in Glasgow coma scores,

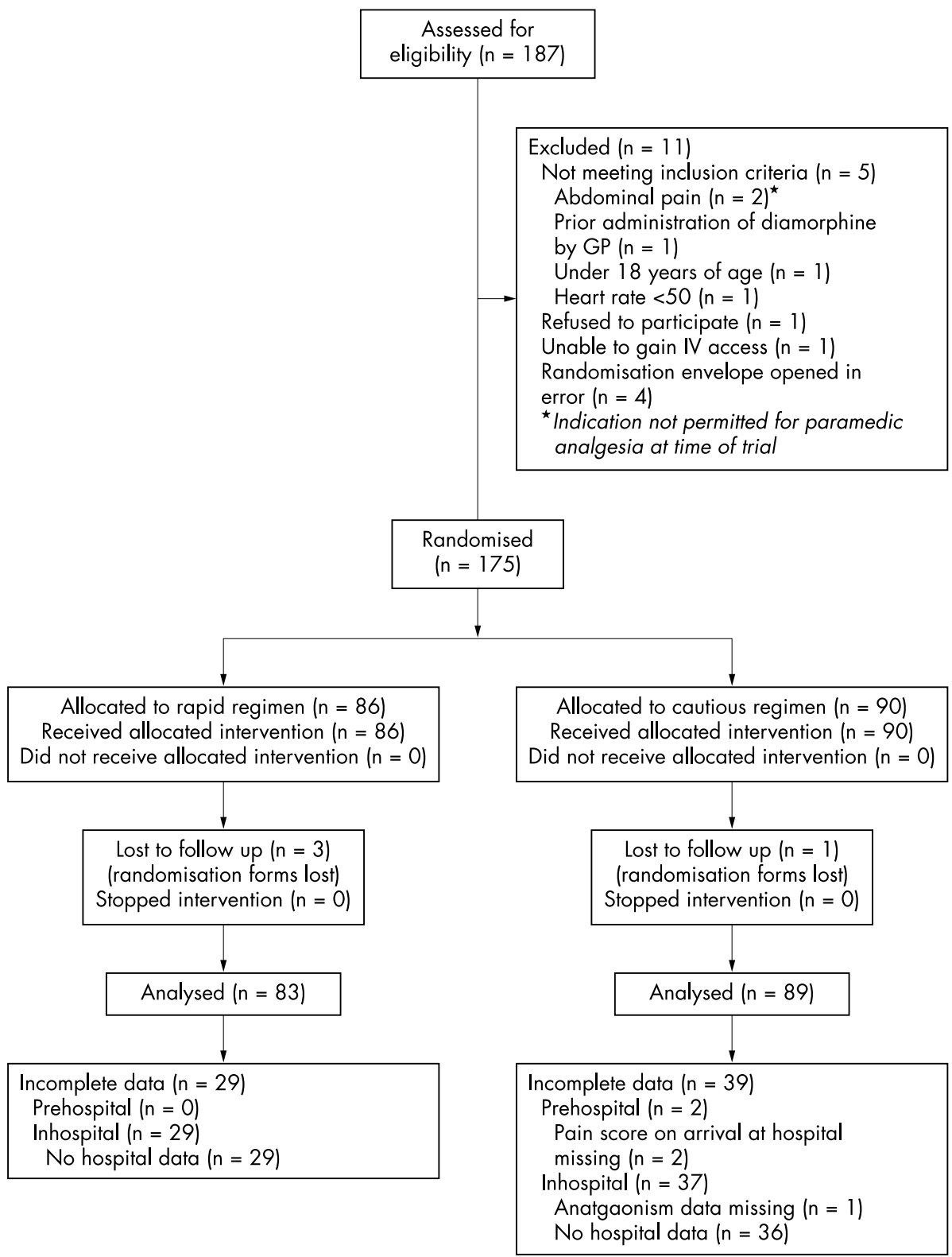

Figure 1 Patient recruitment (Consort style flowchart). Four randomisation envelopes were opened out of sequence-the data from these patients

Not meeting inclusion criteria $(\mathrm{n}=5)$

by $\mathrm{GP}(\mathrm{n}=1)$

Under 18 years of age $(n=1)$

Heart rate $<50(n=1)$

Refused to participate $(\mathrm{n}=1)$

to gain IV access $(n=$

error $(n=4)$

Indication not permitted for paramedic

analgesia at time of trial have been included in the analysis. 
Table 1 Analgesic efficacy and side effects

\begin{tabular}{|c|c|c|c|c|}
\hline & $\begin{array}{l}\text { Rapid } \\
\text { regimen }(2 \times 10 \mathrm{mg})\end{array}$ & $\begin{array}{l}\text { Cautious } \\
\text { regimen }(4 \times 5 \mathrm{mg})\end{array}$ & Difference & $\mathrm{p}$ Value for difference $(95 \% \mathrm{CI})$ \\
\hline Mean total dose of nalbuphine & $14.8 \mathrm{mg}$ & $10.7 \mathrm{mg}$ & $4.1 \mathrm{mg}$ & $<0.001$ \\
\hline Mean change in pain score & 4.29 & 3.49 & 0.79 & $0.028(0.09$ to 1.5$)$ \\
\hline $\begin{array}{l}\text { Patients with a pain score }>3 \\
\text { immediately before A\&E admission (\%) }\end{array}$ & $44(53)$ & $48(55)$ & $2 \%$ & $0.761(-17.0$ to $12.8 \%)$ \\
\hline $\begin{array}{l}\text { Patients receiving hospital analgesia } \\
\text { within } 30 \text { minutes of arrival (\%) }\end{array}$ & $8(15)$ & $6(11)$ & $4 \%$ & $0.583(-10.0$ to $17.1 \%)$ \\
\hline Change in pulse rate & -5.20 & -3.00 & 2.20 & $0.284(-6.26$ to 1.85$)$ \\
\hline Change in respiratory rate & -2.29 & -1.63 & 0.66 & 0.579 \\
\hline Change in systolic BP & -1.75 & -6.28 & 4.53 & 0.108 \\
\hline Change in GCS & -0.14 & -0.23 & 0.09 & 0.348 \\
\hline Any side effect (\%) & $51(62)$ & $36(41)$ & $21 \%$ & 0.004 (6.0 to $35.0 \%)$ \\
\hline Drowsiness (\%) & 35 (42) & $19(21)$ & $21 \%$ & $0.003(7.0$ to $34.1 \%)$ \\
\hline Dizziness (\%) & $21(25)$ & 15 (17) & $8 \%$ & $0.143(-3.8$ to $20.8 \%)$ \\
\hline Nausea or vomiting (\%) & $17(21)$ & $14(16)$ & $5 \%$ & $0.338(-6.9$ to $16.6 \%)$ \\
\hline
\end{tabular}

however, and it is suggested that drowsiness may be a beneficial effect for distressed patients.

No antiemetic agent was administered to patients during this study. The incidence of nausea or vomiting was higher in this trial $(21 \% \vee 16 \%$ for rapid and cautious regimen respectively) than in a previous low dose study, ${ }^{6}$ suggesting a dose related effect.

Paramedics did not give the maximum dose of nalbuphine to patients continuing to report significant pain. In both groups, the total dose administered was identical for patients who achieved adequate analgesia and those that did not. This was not accounted for by differences in on-scene time, journey time to hospital, or initial pain score, and would appear to imply poor compliance to both regimens. We were unable to determine why this was the case.

Although missing hospital data prevented identification of the true incidence of nalbuphine related opioid antagonism, the limited evidence available suggested that it did occur. This has been reported in a previous study, ${ }^{14}$ although others have not observed this effect. ${ }^{15} 16$

In conclusion, a rapid dosing regimen of nalbuphine is more effective than and equally as safe as a cautious regimen. The incidence of nausea or vomiting is significant for both regimens, and research is required to determine an optimum antiemetic drug. Although pain scores fell in both groups, over half of all patients continued to suffer from significant pain before arrival at hospital. Despite this, paramedics often failed to administer the maximum permitted dose. Further research is required to determine why this was the case, and whether the availability of a higher maximum dose of nalbuphine (or the use of morphine) would result in a reduction in the proportion of patients continuing to suffer pain despite paramedic administered analgesia.

\section{ACKNOWLEDGEMENTS}

We thank Dr Robert Newcombe, who provided valuable advice on statistical methodology, and Chris Moore, who helped prepare much of the study paperwork. Comments made by Professor Douglas Chamberlain and Dr Mick Colquhoun and three anonymous reviewers helped improve early drafts of this paper.

\section{Contributors}

Richard Whitfield conceived the idea for this research. Malcolm Woollard, Tim Jones, Richard Whitfield, and Gwyn Thomas designed the study. Malcolm Woollard analysed the data and wrote the first draft of this paper. Richard Whitfield, Ken Smith, Glyn Thomas, Christine Hinton, and Gwyn Thomas collected the study data, contributed to the study design, and edited the paper. Malcolm Woollard is the study guarantor.

\section{Authors' affiliations}

M Woollard, R Whiffield, Pre-hospital Emergency Research Unit, Welsh Ambulance Services NHS Trust/University of Wales College of

Medicine, Cardiff, UK

K Smith, T Jones, G Thomas, G Thomas, C Hinton, Welsh Ambulance Services NHS Trust

Funding: none.

Conflicts of interest: none declared.

\section{REFERENCES}

1 Stene JK, Stofberg L, MacDonald G, et al. Nalbuphine analgesia in the prehospital setting. Am J Emerg Med 1988;6:634-9.

2 Chambers JA, Guly HR. Prehospital intravenous nalbuphine administered by paramedics. Resuscitation 1994;27:153-8.

3 Jamidar HA, Crooks SW, Adgey AA. Nalbuphine versus diamorphine early in the course of suspected myocardial infarction. Eur Heart $J$ 1987;8:597-602.

4 Nikoda VV, Lebedeva RN, Artamoshina MP, et al. Comparative evalauation of the use of nalbuphine and buprenoriphine in prehospital care. Anesteziol Reanimatol 1998;5:23-8.

5 Dempsey C. Nubain Audit. Ambulance UK 1996;11:6-7.

6 Woollard $M$, Jones T, Pitt K, et al. Hitting them where it hurts? Low dose nalbuphine therapy. Emerg Med J 2002;19:565-70.

7 Bolton JE, Wilkinson RC. Responsiveness of pain scales: a comparison of three pain intensity measures in chiropractic patients. J Manipulative Physiol Ther 1998;21:1-17.

8 Bondestam E, Hovgren K, Gaston JF, et al. Pain assessment by patients and nurses in the early phase of acute myocardial infarction. J Adv Nurs 1987; 12:677-82.

9 Price DD, Bush FM, Long S, et al. A comparison of pain measurement characteristics of mechanical visual analogue and simple numerical rating scales. Pain 1994;56:217-26.

10 Ekblom A, Hansson P. Pain intensity measurements in patients with acute pain receiving afferent stimulation. J Neurol Neurosurg Psychiatry 1988;51:481-6.

11 Seymour RA. The use of pain scales in assessing the efficacy of analgesics in post-operative dental pain. Eur J Clin Pharmacol 1982;23:441-4.

12 Ohnhaus EE, Adler R. Methodological problems in the measurement of pain: a comparison between the verbal rating scale and the visual analogue scale. Pain 1975; 1:379-84.

13 Moher D, Schulz KF, Altman DG, for the Consort Group. The Consort statement: revised recommendations for improving the quality of reports of parallel-group randomised trials. Lancet 2001;357:1191-4.

14 Houlihan KP, Mitchell RG, Flapan AD, et al. Excessive morphine requirements after pre-hospital nalbuphine analgesia. J Accid Emerg Med 1999; 16:29-31.

15 Bailey PL, Clark NJ, Pace NL, et al. Failure of nalbuphine to antagonize morphine: a double-blind comparison with naloxone. Anesth Analg 1986;65:605-11.

16 Kelly AS, Guly HR. Nalbuphine - the optimal pre-hospital analgesic for lower limb fractures? Pre-hospital Immediate Care 1999;3:224-5. 